\title{
Pengenalan Pola Lintasan Berbasis Neural Network Pada Prototype Self-Driving Car
}

\author{
Leonardo Rudolf Manangka ${ }^{1}$, Herwin Suprijono ${ }^{2)}$, Dedi Nurcipto ${ }^{3)}$ \\ 1,2,3) Program Studi Teknik Elektro, Fakultas Teknik Universitas Dian Nuswantoro Semarang \\ e-mail: $\underline{511201500700 @ \text { mhs.dinus.ac.id }}{ }^{1)}, \underline{\left.\text { herwin.suprijono@dsn.dinus.ac.id }^{2}\right)}, \underline{\text { dedi.nurcipto@dsn.dinus.ac.id }}{ }^{3)}$
}

\begin{abstract}
Self-driving cars are an interesting topic to discuss due to the high level of traffic accidents that occur due to human error. Self driving cars are vehicles that can find out about the environment with minimal human intervention. Self driving itself has many development methods such as Light Detection and Ranging (LIDAR), cameras, radars, or a combination of these sensors. This study made a prototype self-driving car using a camera as a sensor and a neural network algorithm for pattern recognition. The pattern recognition in question is the image recognition of the path taken. The data that has been taken will later be converted into a matrix with dimensions of $320 \times 120$ according to the image resolution. Then the data will be trained to recognize the path pattern with the proportion of 7: 3 for training accuracy and validation accuracy. The resulting prediction has an accuracy of $76.86 \%$ for training accuracy and $75.24 \%$ for validation accuracy.
\end{abstract}

Keywords: Neural Network, Self-Driving Car, Camera

\section{ABSTRAK}

Self driving car menjadi topik yang menarik untuk dibahas karena tingginya tingkat kecelakaan lalu lintas yang terjadi akibat human error. Self-driving car merupakan kendaraan yang dapat mengetahui lingkungan dengan sedikit campur tangan manusia. Self-driving sendiri memiliki banyak metode pengembangan seperti Light Detection and Ranging (LIDAR), kamera, radar, atau kombinasi dari sensor tersebut. Penelitian ini membuat prototype self-driving car dengan menggunakan kamera sebagai sensor dan algoritma jaringan saraf tiruan untuk pengenalan pola. Pengenalan pola yang dimaksud adalah pengenalan gambar dari jalur yang diambil. Data yang telah diambil nantinya akan diubah menjadi matriks dengan dimensi 320x120 sesuai resolusi gambar. Kemudian data akan dilatih untuk mengenali pola jalur dengan proporsi 7: 3 untuk akurasi pelatihan dan akurasi validasi. Prediksi yang dihasilkan memiliki akurasi $76,86 \%$ untuk akurasi pelatihan dan $75,24 \%$ untuk akurasi validasi.

Kata kunci: Jaringan Syaraf Tiruan, Self-Driving Car, Kamera

\section{Pendahuluan}

elf driving cars menjadi topik yang menarik untuk

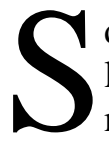
dibahas dikarenakan tingkat kecelakaan lalu lintas yang banyak terjadi karena faktor kesalahan manusia. Angka kecelakaan lalu lintas yang disebabkan oleh faktor kesalahan manusia mencapai $61 \%$, faktor kendaraan $9 \%$, faktor prasarana dan lingkungan $30 \%[1]$. Karena tingginya kecelakaan lalu lintas diakibatkan oleh faktor kesalahan manusia, maka penelitian tentang self driving diperlukan untuk membantu mengurangi angka kecelakaan yang disebabkan oleh faktor kesalahan manusia.

Self driving cars adalah sebuah kendaraan yang dapat mengetahui lingkungan sekitar dengan sedikit campur tangan manusia. Self driving sendiri memilik banyak metode pengembangan seperti Light Detection and Ranging (LIDAR), kamera, radar, ataupun kombinasi dari sensor tersebut[2]. Penggunaan sensor tersebut bertujuan untuk mengenali lingkungan sekitar seperti mark jalan dan rambu-rambu lalu lintas.

Penelitian ini akan menggunakan prototype dengan 4 motor DC sebagai aktuator, kamera sebagai sensor, Raspberry Pi sebagai pemrosesan gambar dan komputer sebagai pemrosesan Neural Network (NN). $N N$ adalah paradigma pengolahan informasi yang terinspirasi oleh sistem saraf biologis, seperti proses informasi otak manusia. Struktur dari sistem pengolahan informasi ini terdiri dari sejumlah besar pemrosesan yang saling berhubungan (neuron) yang bekerja serentak untuk menyelesaikan masalah tertentu. $N N$ bekerja seperti cara kerja manusia, yaitu belajar melalui contoh. Sebuah $N N$ dikonfigurasikan untuk aplikasi tertentu seperti pengenalan pola, klasifikasi data, melalui proses pembelajaran[3]. Penelitian ini ingin membangun prototype self driving cars dengan menerapkan metode $N N$ yang digunakan untuk mengenali lingkungan sekitar seperti arah jalan.

Agar penelitian ini dapat dilakukan lebih fokus, maka perlu dibatasi variabelnya. Pada penelitian ini porototype self-driving car dibatasi hanya pada arah pergerakannya saja. Seperti pengenalan pola jalur lurus, pola garis belok kanan dan kiri.

\section{TEORI DASAR}

\section{A.Self-Driving}

Self driving merupakan salah satu cara mengendalikan mobil dengan sedikit campur tangan manusia. Self driving menggunakan sensor sebagai cara untuk mengenali lingkungan sekitar. Pengenalan tersebut berupa mark jalan, rambu-rambu lalu lintas, 
mobil, dan juga pejalan kaki. Sensor yang digunakan antara lain dapat berupa LIDAR, kamera, GPS, radar atau gabungan dari sensor tersebut[2].

Self driving menurut Society of Automotive Engineers (SAE) memiliki 6 tingkatan.

- Level 0, semua sistem dikendalikan oleh manusia

- Level 1, beberapa sistem seperti kecepatan dan rem otomatis dikendalikan oleh mobil satu per satu.

- Level 2, mobil dapat menawarkan opsi seperti acceleration and steering tapi membutuhkan manusia untuk beroperasi dengan aman.

- Level 3, mobil dapat mengatur keamanan pada kondisi tertentu, tapi pengemudi dapat mengambil alih ketika diberi notifikasi.

- Level 4, mobil dapat beroperasi secara otomatis, meski tidak semuanya.

- Level 5, self driving diterapkan secara menyeluruh dikondisi apapun.

Dari beberapa level diatas level $0-2$ pengemudi memonitor lingkungan mengemudi, sedangkan level 3 5 self driving memonitor lingkungan mengemudi[9].

\section{B. Neural Network}

$N N$ merupakan pengolahan informasi yang

terinspirasi dari sistem saraf biologis manusia.

Pengolahan informasi ini terdiri dari jumlah pemrosesan yang saling terhubung atau disebut dengan neuron, yang berkerja untuk menyelesaikan masalah tertentu. Neural network bekerja seperti jaringan saraf manusia melalui tahap pembelajaran berupa contohcontoh data yang diberikan. Misalnya untuk mengenali pola atau klasifikasi data melalui tahap pembelajaran. Gambar 1. Arsitektur Neural Network

merupakan arsitektur $N N$.

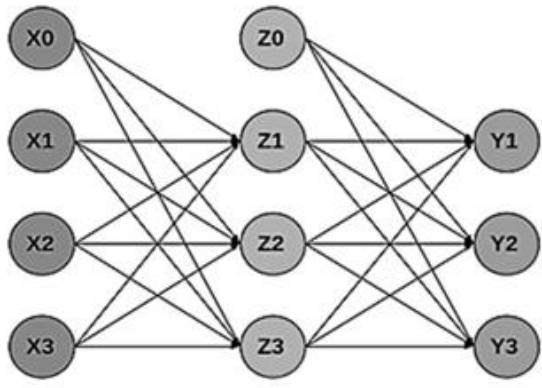

Gambar 1. Arsitektur Neural Network

$N N$ memiliki arsitektur yang tersusun menjadi tiga lapisan antara lain, input layer, hidden layer dan output layer. Input layer merupakan lapisan yang bertugas menerima inputan dari luar seperti data sensor. Hidden layer merupakan lapisan yang dimana nilai bobot dan fungsi aktivasi berada. Output layer merupakan hasil pemecahan suatu masalah. Gambar 2 merupakan model matematis $N N$.

Gambar 2. Model matematis Neural Network

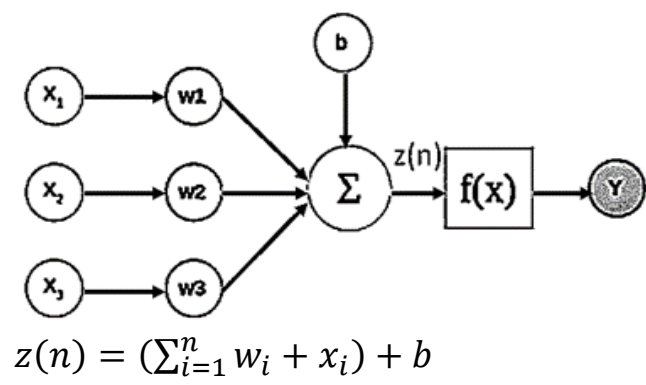

$$
\begin{aligned}
\text { Dimana }: \mathrm{z}(\mathrm{n}) & =\text { hasil dari jumlah input } \\
\mathrm{w} & =\text { weight } \\
\mathrm{x} & =\text { nilai input }
\end{aligned}
$$

Setelah didapatkan nilai $\mathrm{z}(\mathrm{n})$ kemudian diteruskan ke fungsi aktivasi tertentu $f(X)$ dan didapat output neuron adalah Y.

Backpropagation merupakan mekanisme utama dimana $N N$ belajar. Backpropagation memiliki tiga tahap yang harus dilakukan dalam tahap pelatihan. Pertama adalah perambatan maju (forward propagation), kedua tahap perambatan balik dan terakhir adalah perubahan bobot dan bias. Arsitektur ini terdiri dari input layer, hidden layer dan output layer.

Kelebihan-kelebihan yang diberikan oleh neural network antara lain:

1. Belajar adaptive: Kemampuan untuk mempelajari bagaimana melakukan pekerjaan berdasarkan data yang diberikan untuk pelatihan atau pengalaman awal.

2. Self-Organisation: Sebuah NN dapat menciptakan suatu pola pengetahuan melalui pengaturan diri atau kemampuan belajar.

3. Real Time Operation: Perhitungan $N N$ dapat dilakukan secara paralel sehingga perangkat keras yang dirancang dan diproduksi secara khusus dapat mengambil keuntungan dari kemampuan ini[3].

\section{METODE PENELITIAN}

Tahap awal penelitian ini dilakukan pengumpulan informasi dan refrensi dari penilitian terdahulu. Beberapa hal yang dibutuhkan pada penilitian ini yaitu pembuatan alur penelitian, perancangan hardware, dan perancangan software. Kemudian dilakukan pengumpulan data, pelatihan self driving car, dan tahap terakhir adalah pengujian self driving car.

\section{A. Perancangan Hardware}

Perancangan hardware pada penelitian ini menggunakan Raspberry $P i$ yang terhubung dengan sensor yaitu berupa kamera, serta Raspberry Pi yang terhubung dengan driver motor dimana driver motor menggerakan motor DC. Mini komputer Raspberry Pi 
bertugas untuk mengambil gambar yang nantinya akan dikirim ke laptop secara nirkabel. Gambar 3 merupakan diagram blok sistem.

Gambar 3. Diagram blok sistem

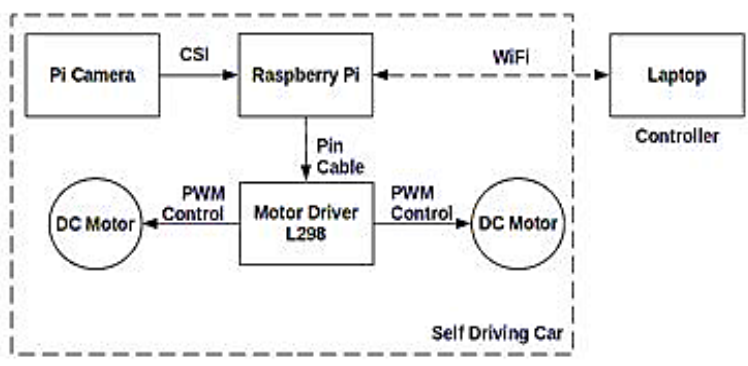

Laptop berfungsi sebagai controller, pengolahan neural network, penerima data gambar dari Raspberry $P i$ dan menyimpan data gambar serta mengirim hasil proses neural network kembali ke Raspberry Pi. Raspberry $P i$ berfungsi untuk mengambil gambar dengan menggunakan kamera, mengirim data gambar ke laptop dan mengirim sinyal Pulse Width Modulation (PWM) ke rangkaian driver motor untuk menjalankan motor. Laptop dan Raspberry Pi menggunakan jaringan $W i F i$ untuk berkomunikasi.

\section{B. Pengumpulan Data}

Tahap pengumpulan data dilakukan dengan caramenjalankan self driving car secara manual, dimana gambar diambil ketika mobil berjalan, menggunakan laptop sebagai pengendali secara nirkabel. Data yang diambil berupa gambar jalan dengan resolusi 320 x 240 pixel. Input navigasi yang dikirim dari laptop berguna sebagai label yang nantinya juga akan disimpan sebagai klasifikasi pengenalan gambar. Data yang diambil nantinya akan disimpan di laptop sebagai data set training $N N$ yang berfungsi sebagai data latih algoritma $N N$. Berikut ini adalah gambar flowchart alur program dapat dilihat pada Gambar 4.

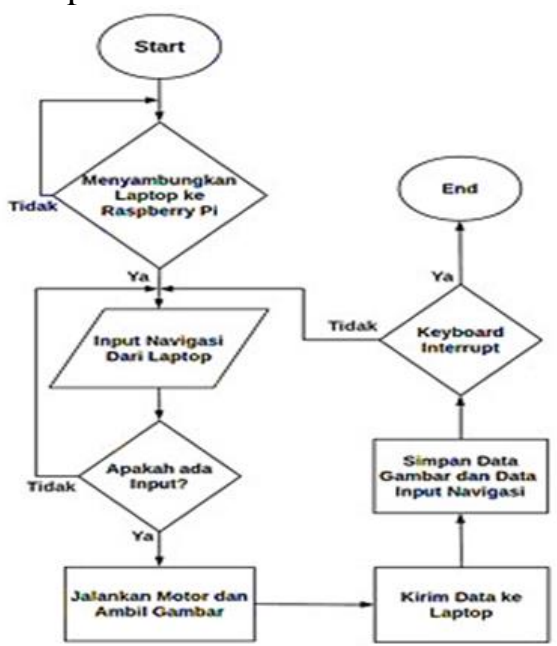

Gambar 4. Flowchart alur program pengumpulan data
Tahap pelatihan, dilakukan dengan mengkonversi gambar kebentuk array yang merupakan suatu tipe data terstruktur yang dapat menyimpan banyak data dengan suatu nama yang sama dan menempati tempat di memori yang berurutan serta bertipe data sama. Kemudian data

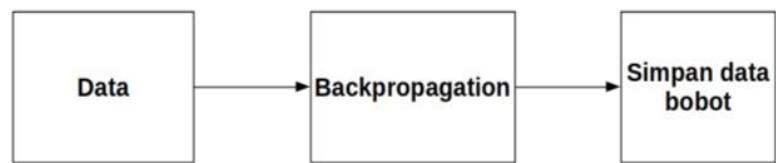

gambar yang sudah dikonversi akan dipasangkan dengan data label yang sudah disimpan. Setelah itu data akan dilatih dengan menggunakan metode backpropagation. Struktur $N N$ memiliki input layer sebanyak data array yang disimpan, 1 hidden layer, 4 output layer yang berupa input navigasi seperti maju, mundur, kanan dan kiri. Kemudian setiap perubahan pada bobot akan disimpan, yang nantinya akan digunakan sebagai data acuan pada saat pengujian. Gambar 5 merupakan gambar diagram blok pelatihan

$$
\text { Gambar 5. Diagram blok pelatihan }
$$

\section{Pengujian}

Tahap pengujian, dilakukan dengan menerapkan hasil pelatihan dengan jalur lintasan. Pada tahap ini self driving car akan mengambil data dari lingkungan yang baru kemudian validasi data dengan data bobot yang tersimpan sebagai

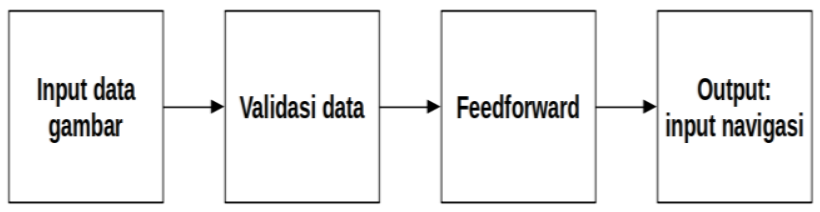

acuan. Gambar 6 merupakan gambar diagram blok pengujian. Gambar 6. Diagram blok pengujian

Setelah proses feedforward akan dihasilkan output berupa input navigasi untuk menentukan arah gerakan dari mobil. Input navigasi ini yang akan dikirim ke mikrokontroler sebagai perintah yang akan mengatur kecepatan motor.

\section{E. Analisis}

Pada tahap analisis akan dilakukan pengujian pada sistem self driving. Pengujian ini berupa menguji kepresisian sistem dalam menangani lintasan yang dibuat. Akan ada 4 lintasan uji yang akan menguji tingkat kepresisian self-driving. Lintasan uji pertama memiliki bentuk melingkar dengan satu arah belokan dan pola garis berwarna hitam, lintasan uji kedua memiliki bentuk melingkar dengan lintasan yang lebih rumit dan pola garis berwarna hitam, lintasan uji ketiga memiliki bentuk persegi panjang dan pola garis berwarna hitam, dan lintasan keempat memiliki pola garis berwarna putih.

\section{Pelatihan}




\section{A. Pengumpulan data}

\section{PEMBAHASAN}

Pada tahap ini dilakukan pengumpulan data dengan menjalankan self-driving car secara manual dimana self-driving car dijalankan dengan mengikuti pola-pola lintasan yang dibuat untuk proses pelatihan. Gambar yang diambil dalam proses ini digunakan sebagai pola pelatihan untuk input $N N$ dan kontrol navigasi sebagai label untuk output $N N$. Gambar pola lintasan yang diambil dari kamera yang terpasang pada self-driving car dapat dilihat pada Gambar 7, Gambar 8, dan Gambar 9.

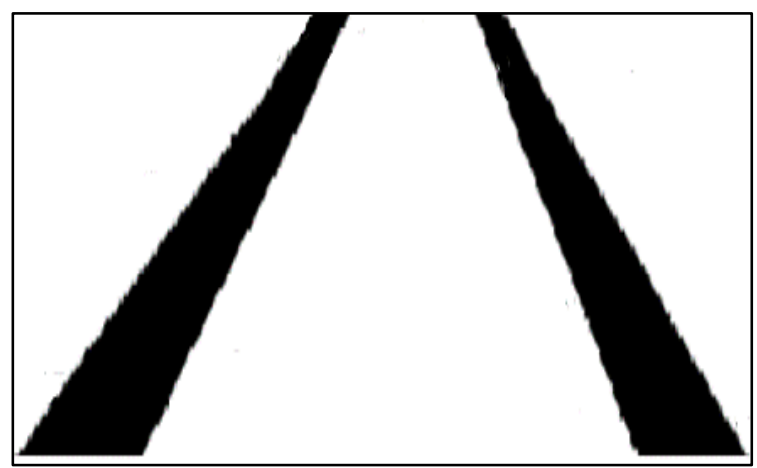

Gambar 7. Pola Pelatihan Jalan Lurus

Citra pola lintasan yang diambil oleh kamera nantinya akan diberi label 0 untuk jalur lurus, label 1 untuk belok kiri dan label 2 untuk belok kanan. Gambar dan label tersebut yang nantinya akan menjadi data pelatihan untuk $N N$.

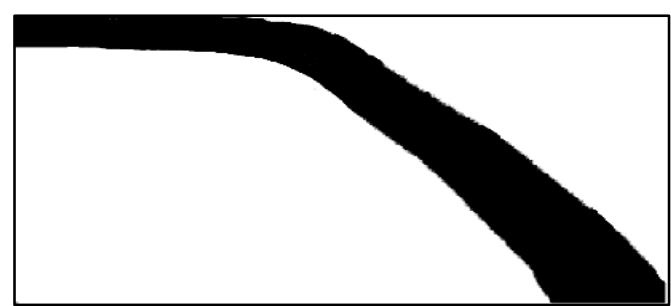

Gambar 8. Pola Pelatihan Belok Kanan

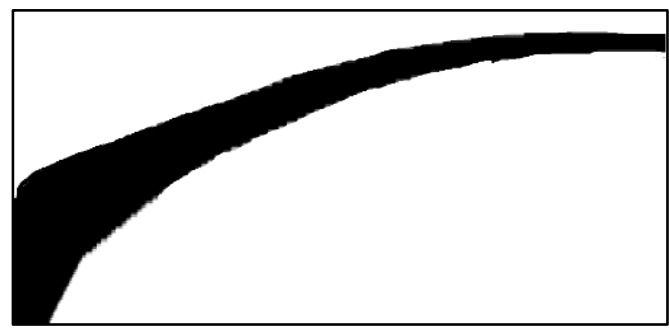

Gambar 9. Pola Pelatihan Belok Kiri

\section{B. Preprocessing data}

Citra pola lintasan diubah ke bentuk matrix dengan menggunakan modul Numpy kemudian disimpan dengan format .npz yang dapat dibuka dengan modul Numpy. Didalam format .npz berisi file train.npy dan train_labels.npy isi dari file train.npy tersebut dapat dilihat pada Gambar 10.

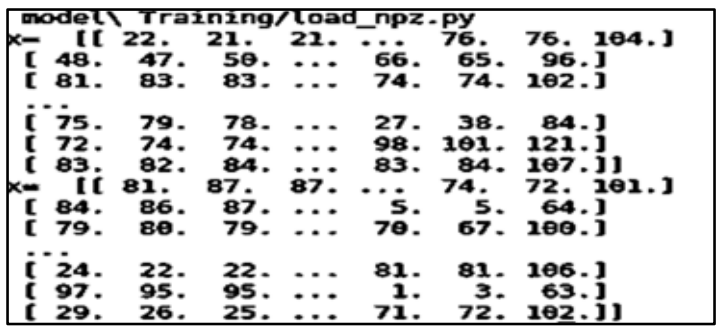

Gambar 10. Isi file train.npy

Array $\mathrm{x}$ merupakan isi dari file train.npy yang merupakan data gambar grayscale yang diubah dalam bentuk matrix memiliki dimensi 320x120, sama dengan luas data citra. Untuk isi dari file train_labels.npy dapat dilihat pada Gambar 11

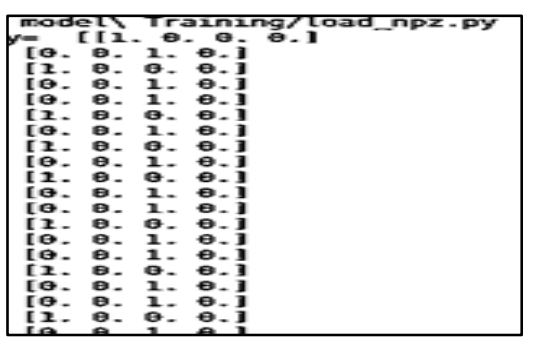

Gambar 11. Isi file train_labels.npy

Array y adalah isi dari file train_labels.npy yang merupakan data label dari gambar grayscale. Kemudian data train.npy akan di normalisasi, hasil normalisasi dapat dilihat pada Gambar 12.

Normalisasi dilakukan dengan cara membagi data train dengan bilangan desimal 255. Normalisasi diperlukan agar mendapat rata-rata mendekati angka nol sehingga proses learning dapat dilakukan lebih cepat.

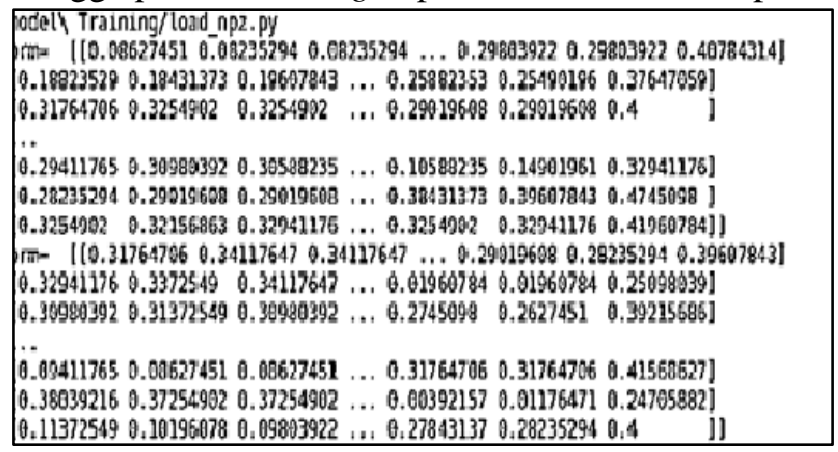

Gambar 12. Normalisasi data training 


\section{Pelatihan Model Neural Network}

Setelah dilakukan pengumpulan dan preprocessing data, selanjutnya data dimasukan ke dalam model neural network.

Pelatihan model neural network yang digunakan adalah backpropagation dengan inputan berupa data array yang diambil dari data train.npy yang sudah di normalisasi. Hasil pelatihan dapat dilihat pada Gambar $\mathbf{1 3}$

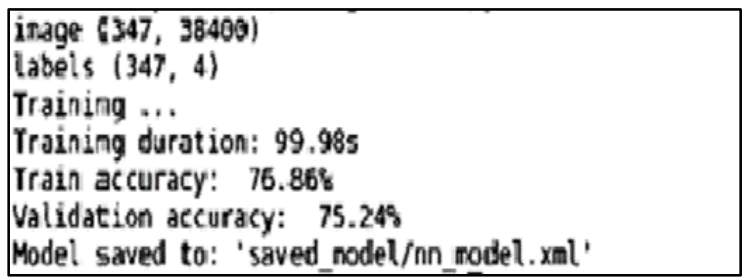

Gambar 13. Hasil training model

Model $N N$ yang dirancang menggunakan input layer sebanyak 38400 angka ini didapatkan dari resolusi gambar yaitu 320 x (240/2), satu hidden layer, dan empat output layers. Iterasi untuk melatih $N N$ sebanyak 100 kali dengan learning rate sebesar 0,01. Model $N N$ ini menggunakan 347 buah citra dan dikonversi menjadi array menggunakan modul Numpy. Dataset kemudian dipisah dengan perbandingan 7:3 dimana 7 adalah data untuk training dan 3 adalah data test. Dari hasil pelatihan model neural network didapatkan training accuracy sebesar $76.86 \%$ dan validation accuracy 75.24\%. Bobot dari training ini akan di simpan dengan nama file nn_model.xml. Data bobot yang disimpan nantinya akan digunakan untuk pengujian dan implementasi self-driving car. Data tersebut menunjukan nilai bobot yang didapat dari hasil training, nilai ini yang akan dipakai untuk menentukan hasil prediksi dalam tahap pengujian dan implementasi.

\section{Pengujian dan Implementasi self-driving car}

Pengujian dan implementasi $N N$ ke prototype selfdriving car dilakukan dengan 4 lintasan berbeda. Lintasan pertama menggunakan lintasan melingkar dan lintasan kedua dilakukan dengan menambahkan berhasil dilakukan oleh self-driving car dengan maksimal 10 putaran. Bentuk lintasan ke-1 dapat dilihat pada Error! Reference source not found.

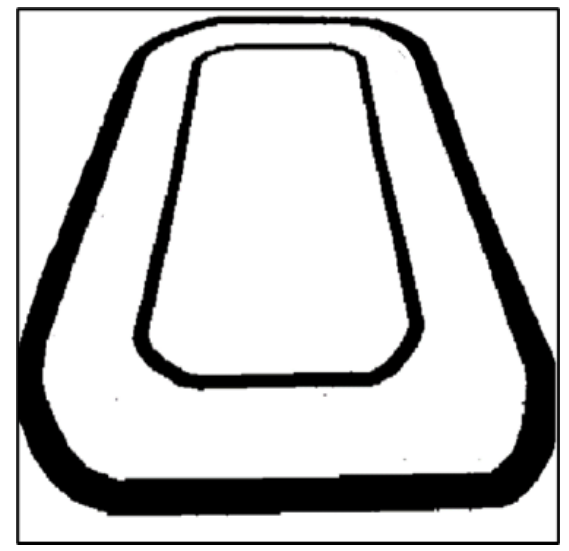

Gambar 14. Bentuk lintasan uji ke-1
Pada pengujian dengan lintasan uji ke-1 dilakukan 10 kali percobaan putaran searah jarum jam (clockwise) dalam 10 kali putaran didapati tingkat keberhasilan sebesar $100 \%$ dan pada 10 kali putaran berlawanan arah jarum jam (counter clockwise) didapati tingkat keberhasilan sebesar $100 \%$.

Untuk pengujian berikutnya dilakukan pada pola lintasan yang lebih komplek bentuk pola lintasan dapat dilihat pada Gambar 16.

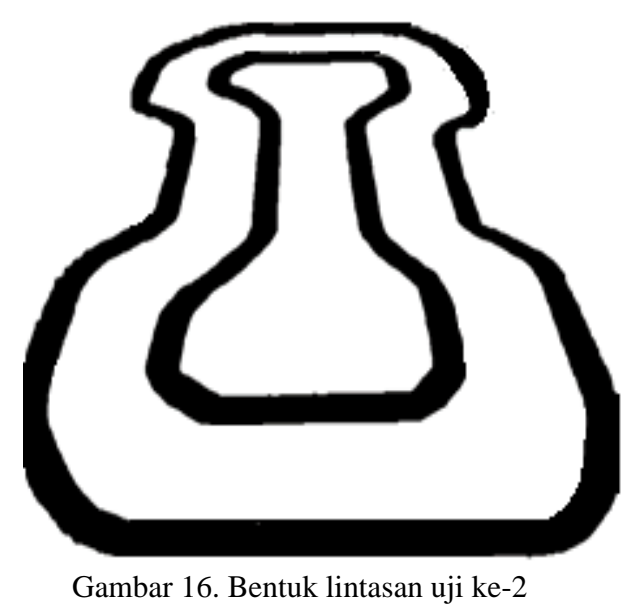

Dengan pola lintasan yang lebih kompleks dibandingkan pola lintasan ke-1 setelah diujicoba dengan cara yang sama dengan uji ke-1 maka NN dapat beradaptasi dengan perubahan pola lintasan yang baru dimana dalam 10 kali putaran uji coba didapati tingkat keberhasilan sebesar $100 \%$ dan 10 kali putaran berlawanan arah jarum jam (counter clockwise) didapati tingkat keberhasilan sebesar $100 \%$.

Kemudian akan dilakukan pengujian ke-3 dengan tikungan sudut $90^{\circ}$ seperti pada Gambar 17 . Dari hasil pengujian didapat keakuran pengujian sebesar $50 \%$. Terjadi kesalahan prototype self-driving car tidak mampu berbelok tetapi justru berjalan lurus.

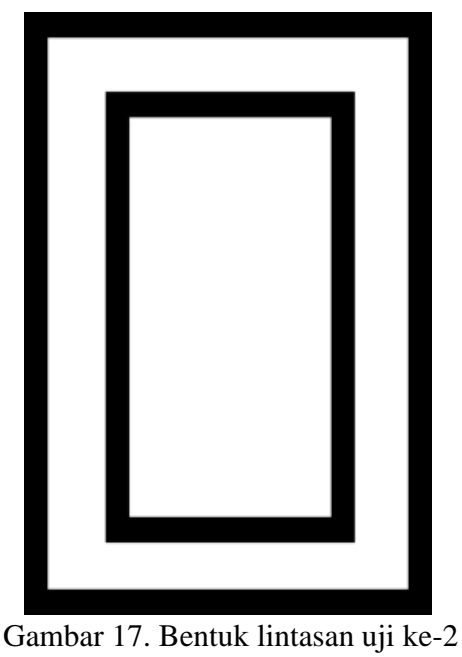

Pengujian ke-4 dilakukan dengan mengganti pola garis berwarna hitam menjadi pola garis berwarna putih. Tujuan pengujian ini untuk mengetahui seberapa baik 
prototype self-driving car dapat memprediksi jalur dengan pola tersebut. Hasil pengujian menunjukkan Prototype self-driving car gagal dalam mengenali pola lintasan berwarna putih disebabkan karena tidak adanya dataset atau pembelajaran pengenalan citra untuk pola lintasan berwarna putih.

\section{KESIMPULAN}

Keakuran dari perdiksi dari $N N$ dalam pengenalan pola lintasan tergantung dari jumlah pola yang dilatih, dari hasil pengujian dengan lintasan ke-1 dan ke-2 menunjukkan keakuratan yang baik karena $N N$ mendapat pembelajaran pola pada kedua lintasan tesebut. Sedangakan untuk percobaan dengan pola lintasan ke -3 dan ke -4 dengan keakuratan $N N$ dalam memprediksi menurun dimana $N N$ tidak dapat mengenal citra pola lintasan yang diberikan hal ini disebabkan $N N$ tidak mendapat dataset pelatihan belokan dengan sudut $90^{\circ}$ dan pola lintasan dengan garis putih.

Untuk meningkatkan keakuratan prediksi dari NN dengan memberikan citra pola-pola yang lebih lengkap dan iterasi pelatihan yang lebih banyak sehingga training accuracy dan validation accuracy semakin baik, tentu nya dengan menggunakan komputasi yang lebih cepat.

Pengembangan berikut nya pada Prototype selfdriving car dapat mengenali halangan misalkan kendaraan lain, halangan di lintasan, rambu-rambu lalu lintas, menanamkan embedded system yang lebih cepat dan menambahkan sistem kendali Prototype selfdriving car.

\section{DAFTAR PUSTaka}

[1] K. K. dan Informatika, "Setiap Jam Rata-Rata 3 Orang Meninggal Akibat Kejelakaan Jalan Di Indonesia," 2017. https://kominfo.go.id/index.php/content/detail/10368/rata-rata-tiga-orang-meninggal-setiap-jam-akibat-kecelakaan-jalan/0/artikel_gpr.

[2] Sumardi, M. Taufiqurrahman, and M. A. Riyadi, "Street mark detection using raspberry pi for selfdriving system," Telkomnika (Telecommunication Comput. Electron. Control., vol. 16, no. 2, pp. 629 634, 2018, doi: 10.12928/TELKOMNIKA.v16i2.4509.

[3] S. K. Kokate, "Review on Autonomous Car using Raspberry Pi," Int. J. Res. Appl. Sci. Eng. Technol., vol. 6, no. 1, pp. 3090-3094, 2018, doi: 10.22214/ijraset.2018.1427.

[4] G. SinghPannu, M. Dawud Ansari, and P. Gupta, "Design and Implementation of Autonomous Car using Raspberry Pi,” Int. J. Comput. Appl., vol. 113, no. 9, pp. 22-29, 2015, doi: 10.5120/19854-1789.

[5] K. McFall, "Using visual lane detection to control steering in a self-driving vehicle," Lect. Notes Inst. Comput. Sci. Soc. Telecommun. Eng. LNICST, vol. 166, pp. 861-873, 2016, doi: 10.1007/978-3-31933681-7_77.
[6] S. Jana, S. Borkar, and M. E. Student, "Autonomous Object Detection and Tracking using Raspberry Pi," Int. J. Eng. Sci. Comput., vol. 7, no. 7, pp. 1415114155, 2017, [Online]. Available: http://ijesc.org/.

[7] W. Farag and Z. Saleh, "Traffic signs identification by deep learning for autonomous driving," IET Conf. Publ., vol. 2018, no. CP747, pp. 22-23, 2018, doi: 10.1049/cp.2018.1382.

[8] M. G. Bechtel, E. McEllhiney, M. Kim, and H. Yun, "DeepPicar: A low-cost deep neural network-based autonomous car," Proc. - 2018 IEEE 24th Int. Conf. Embed. Real-Time Comput. Syst. Appl. RTCSA 2018, pp. 11-21, 2019, doi: 10.1109/RTCSA.2018.00011.

[9] Global Ground Vehicle Standards, “Automated Driving: Levels Of Driving Automation Are Defined In New SAE International Standard J3016," SAE International, 2016. https://www.sae.org/misc/pdfs/automated_driving.pdf.

[10] A. Driving and S. Dimensions, "Autonomes Fahren," Auton. Fahr., 2015, doi: 10.1007/978-3-662-45854-9. 